\title{
Formation of Fallopian tubal fluid: role of a neglected epithelium
}

\author{
Henry J. Leese ${ }^{1}$, Jacqueline I. Tay ${ }^{2}$, Judith Reischl ${ }^{1 *}$ \\ and Sandra J. Downing ${ }^{1}$ \\ ${ }^{1}$ Department of Biology, University of York, PO Box No. 373, York YO10 5YW, UK; and \\ ${ }^{2}$ Department of Obstetrics and Gynaecology, D Floor, Clarendon Wing, Leeds General \\ Infirmary, Belmont Grove, Leeds LS2 9NS, UK
}

\begin{abstract}
Fluid produced and secreted by the Fallopian tube provides the environment in which gamete transport and maturation, fertilization and early embryo development occur. This review describes the composition of oviductal fluid in terms of ions and nutrients such as glucose, lactate, pyruvate and amino acids. The function of oestrogen-specific glycoprotein is discussed. The mechanisms of fluid secretion and agents known to influence fluid production and secretion are described. Clinical implications of abnormal oviductal fluid production and secretion in hydrosalpinx and pelvic inflammatory disease are also discussed.
\end{abstract}

In mammals, fertilization and early embryo development occur in the oviduct (Fallopian tube). The oviduct also acts as a sperm reservoir after mating. Anyone unfamiliar with this information might imagine that the formation of oviductal fluid, the medium in which these processes occur, had been studied extensively. They would be wrong. Compared with the wealth of data on other epithelial tissues, for example, those lining the gastrointestinal tract, kidney tubules and airways, there is a paucity of information on the formation of oviductal fluid. A major reason for the lack of investigation is the success of in vitro fertilization (IVF) and embryo transfer (ET) techniques, in which the oviduct is bypassed, creating the impression that the study of oviductal fluid is somewhat redundant. However, this is akin to saying that there is no need to study the intestine, kidney or airways since people can be kept alive parenterally, by kidney dialysis or by artificial respiration, respectively. Undoubtedly, there is a practical need to improve IVF success rates, ensure the normality of the embryos created and increase knowledge about the first environment to which embryos are exposed.

Because the mechanisms underlying oviductal fluid formation have yet to be elucidated in any detail, the hormonal and nervous control of the processes involved are not fully understood, nor are the possible pharmacological effects, which might have a clinical role. By the same token, the mechanisms that integrate the actions of the myosalpinx (the muscle component of the oviduct) and the endosalpinx (the mucosal lining) have yet to be explored.

This review considers: (i) key features of the composition

Email: hjl1@york.ac.uk

*Present address: Gynaekologische und Ambulatorische Tierklinik, LMU Muenchen, Koenigstrasse 12, 80539 Muenchen, Germany of oviductal fluids; (ii) the few studies that have addressed the mechanisms that underlie oviductal fluid secretion; (iii) the effect of modulators of oviductal fluid secretion and their functional significance; and (iv) clinical implications of research on oviductal secretion.

\section{Oviductal fluid composition and rate of formation}

The composition of oviductal fluid is well documented (Miller and Schultz, 1987; Hunter, 1988; Leese, 1988; Nichol et al., 1992; Dickens et al., 1995; Boatman, 1997; Tay et al., 1997). With regard to ions, oviductal fluid is rich in $\mathrm{K}^{+}$and $\mathrm{HCO}_{3}{ }^{-}$in comparison with plasma. The concentrations of nutrients also differ from those in plasma, and vary with endocrine state. For example, the concentration of glucose in pig oviductal fluid decreases tenfold after ovulation (Nichol et al., 1992, 1998) and sixfold in human oviductal fluid between the follicular phase and midcycle (Gardner et al., 1996). The amino acids present in the highest concentrations are arginine, alanine and glutamate in human (Tay et al., 1997) and glycine, glutamate and alanine in rabbit oviductal fluid (Miller and Schultz, 1987). Glycine, alanine, leucine and phenylalanine are transported to the greatest extent from the vascular compartment into the lumen of the rabbit oviduct (Leese and Gray, 1985). Glycine protects preimplantation mouse embryos against the detrimental effect of inorganic ions (Van Winkle et al., 1990), probably due to its capacity to act as an organic osmolyte (Dawson et al., 1998). Taurine and hypotaurine are major constituents of oviductal fluid and are important in supporting the viability of gametes and preimplantation embryos (Boatman, 1997). In rabbits, fluid production is highest at oestrus, then declines during pseudopregnancy (Bishop, 1956; Richardson and Oliphant, 1981; Gott et al., 1988). In monkeys, there is an increase in oviductal fluid secretion at 
ovulation (for review, see Perkins, 1974). In cows, oviductal fluid is produced at a rate of $0.2 \mathrm{ml}$ per day at dioestrus and at $2.0 \mathrm{ml}$ per day at oestrus (Roberts et al., 1975). More fluid is produced by cells in the rabbit ampulla than by cells in the isthmic region, reflecting the greater surface area of the ampulla cells (Leese, 1983). In ewes, oestrogen treatment increases fluid secretion, whereas progesterone decreases fluid secretion and antagonizes the effect of oestrogen (Mastroianni et al., 1961, McDonald and Bellvé, 1969). In ovariectomized rabbits and ewes, the secretory rate of the oviduct is maintained at a steady level a little below that observed for the luteal phase of the cycle (Perkins, 1974). Treatment of ovariectomized females with even low doses of oestradiol results in a marked increase in oviduct secretion. The mechanism by which ovarian steroids modulate oviductal fluid secretion is not fully understood. Both ciliated and non-ciliated secretory cells of the oviductal epithelium are sensitive to variations in circulating steroid concentrations (Murray, 1995). Oestrogen induces hypertrophy, maturation and increases in cell height of non-ciliated secretory epithelial cells and can partially restore the ciliated phenotype in vitro (Comer et al., 1998), whereas progesterone causes atrophy and diminished secretory activity. Such changes to cell morphology indicate changes in synthetic activity that contribute to the variation in oviductal fluid production. Steroid hormones may influence the rate of fluid secretion by modulating the movement of ions across the oviductal epithelium. In cultured tracheal cells, steroid hormones regulate the balance of $\mathrm{Na}^{+}$absorption and $\mathrm{Cl}^{-}$secretion (Zeitlin et al., 1989) and, in the kidney tubule, oestrogen enhances $\mathrm{Na}^{+}$and $\mathrm{Cl}^{-}$ transport (Verlander et al., 1998). Therefore, it is possible that steroid hormones have similar effects in the oviduct.

\section{Oviduct-specific glycoproteins}

Glycoproteins specific to the oviduct are synthesized and secreted into the oviductal fluid in all species that have been examined. The quantities of oviductal glycoproteins are highest during the periovulatory period and decrease thereafter. Thus, the synthesis and secretion of oviductspecific glycoproteins occur in response to oestrogen stimulation (Abe et al., 1998), whereas progesterone appears to have little influence. However, Sun et al. (1998) suggested that $\mathrm{LH}$ rather than oestrogen is the stimulus for oviduct-specific glycoprotein synthesis and secretion. Oviduct-specific glycoproteins bind to the zona pellucida of oocytes and embryos, indicating a role in early development (Verhage et al., 1997, Staros and Killian, 1998). Oestrus-associated oviduct-specific glycoprotein (OSGP) from different species shows strong sequence homology, indicating conservation of amino acid sequence and structure during evolution. In hamsters, the carbohydrate portion of the glycoprotein may mediate adherence of spermatozoa to the epithelium of the lower isthmus (Demott et al., 1995). Binding of OSGP to the oocyte may enhance fertilization (Martus et al., 1998) and OSGP has been reported to enhance sperm capacitation and binding to the zona pellucida and to facilitate sperm penetration (for reviews, see Abe and Hoshi, 1997; Verhage et al., 1997). The hamster OSGP associates with both the oocyte and the spermatozoon, possibly enhancing penetration and fertilization by influencing the time course of acrosomal enzyme secretion or degradation (Boatman and Magnoni, 1995). Hunter (1994) proposed that, by increasing the viscosity of luminal fluid, oviduct glycoproteins could stabilize the microenvironments immediately surrounding the gametes and embryo, preventing dispersal of essential nutrients and ions, particularly during ciliary beating or muscular contraction. This increase in viscosity would buffer the embryo against osmotic changes and fluctuations in the constituents of luminal fluid. Production of a more viscous fluid could also reduce loss of luminal fluid into the peritoneal cavity.

Although the oviduct-specific glycoproteins have been examined in detail, their physiological roles remain elusive. Since eggs, spermatozoa and early embryos can survive in vitro, it is logical to postulate a putative function for these glycoproteins unique to the situation in vivo. One possibility relates to the need for immunological protection, which is required in vivo but not in vitro. Indeed, Oliphant et al. (1984) suggested that rabbit oviductal fluid contains an inhibitor of complement activity that prevents the immobilization of spermatozoa, and that this inhibition may be attributed to oviduct-specific sulphated glycoproteins.

\section{Mechanisms of oviductal fluid secretion}

Fluid movements across secretory epithelia are secondary to the movements of solutes, particularly ions. In secretory epithelia, chloride ion movements from the basal to apical poles of the cells play a significant role in providing the driving force for water movement (Quinton, 1990). A lower intracellular $\mathrm{Na}^{+}$concentration is maintained by the $\mathrm{Na}^{+}-\mathrm{K}^{+}$ATPase, with uptake of $\mathrm{Cl}^{-}$via the $\mathrm{Na}^{+}-\mathrm{K}^{+}-\mathrm{Cl}^{-}$ cotransporter at the basolateral membrane. The apical surface becomes permeable to $\mathrm{Cl}^{-}$, which allows the anion to move down an electrochemical gradient into the lumen. The ion movements generate an electrical force that drives $\mathrm{Na}^{+}$paracellularly through the tight junctions between the cells. In other secretory epithelia, localized accumulation of ions in the intercellular spaces is thought to create areas of high osmotic pressure. Water follows these ion movements to restore the osmotic equilibrium and thus accumulates in the lumen (Diamond, 1971; Quinton, 1990). Similar mechanisms are likely to operate in the oviduct. Epithelial cells increase in height at oestrus (Murray, 1995), when fluid production is maximal. This increase in height may increase the area of intercellular space available for localized accumulation of ions. Increased viscosity of luminal fluid, due to production and secretion of oestrusassociated glycoproteins, may also prevent rapid diffusion, thereby assisting accumulation of ions into microenvironments with high osmolarity (Hunter, 1994). 


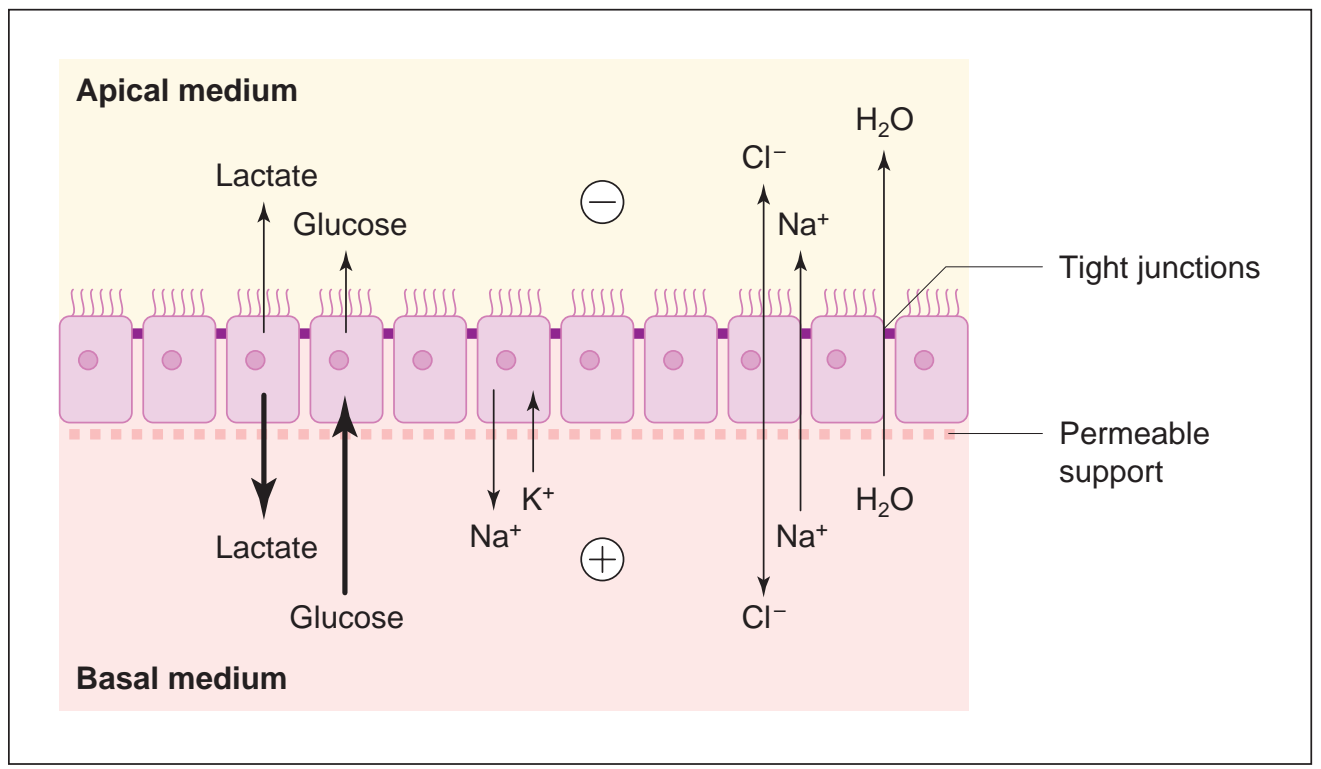

Fig. 1. Schematic diagram of oviduct epithelial cells grown in primary culture as a polarized layer on a permeable support (shown as a heavy dashed line). The diagram represents the (cilated and non-ciliated) cells as a confluent monolayer, and shows the movement of ions across the monolayer with the apical medium negative with respect to the basal medium. Movement of glucose is shown predominantly from the basal medium into the cells and into the fluid secreted into the apical medium. Movement of lactate is predominantly into the basal medium.

In the oviduct, these mechanisms are probably localized to the non-ciliated, as opposed to the ciliated, cells that comprise the epithelial lining, but only limited phenotypic characterization of the two cell types has been carried out (Comer et al., 1998). The epithelial cells must be maintained in a functioning state in vitro for their transport properties to be examined. Brunton and Brinster (1971) used the method of Ussing and Zerahn (1951), originally developed for frog skin, and mounted whole segments of rabbit oviduct between two identical solutions bathing the apical and basal sides. The tissue maintained a transmural electrical potential difference and $\mathrm{Cl}^{-}$ions were shown to move preferentially in the secretory (that is, basal to apical) direction, a finding confirmed by Gott et al. (1988) using a vascular perfusion preparation of the rabbit oviduct. Gott et al. (1988) also found that ion secretion could be blocked by inhibitors of $\mathrm{Cl}^{-}$transport. Although it is likely that the data obtained using the Ussing preparation and vascular perfusion reflect epithelial cell secretory activity, the interpretation of the results is confounded by the presence of underlying stroma and muscle tissue. This problem may be overcome by using a preparation for the maintenance of the epithelial cells as a polarized confluent layer in primary culture (Dickens et al., 1993, 1996). The great advantage of this technique is that the epithelial cells are maintained in their correct spatial arrangement, with the basal medium (which is equivalent to extracellular fluid in vivo) separated from the apical medium (which is equivalent to the oviduct lumen) (Fig. 1).
Changes in ion fluxes may be detected by monitoring the transepithelial potential difference, which represents the difference in ion concentration across the epithelium, and the short circuit current $\left(_{\text {scc }}\right.$ the current required to clamp the transepithelial potential difference to $0 \mathrm{mV}$ ) which represents the net active transepithelial ion transport. Treatment of cultured epithelial cells with blockers of chloride channels or incubation in chloride-free medium reduced potential difference and $\mathrm{I}_{\mathrm{scc}}$ markedly, confirming that chloride ion flux is important for the generation of transepithelial potential difference and fluid secretion in this tissue (Downing et al., 1997; Reischl et al., 2000).

The same method was used to examine the transport of non-electrolytes into the rabbit oviduct lumen. Thus, Edwards and Leese (1993) showed that glucose was transported preferentially in a basal to apical direction by facilitated diffusion. Lactate formed as a result of glucose metabolism and appeared predominantly in the basal medium, further confirming the polarity of the preparation (Fig. 1). The same phenomenon is found in human oviductal epithelial cells (Dickens et al., 1996). A decrease in the rates of glucose and lactate appearance on the apical side of the rabbit epithelial cells was apparent by 3 days after mating, coincident with the time in vivo when the embryos would have passed from the oviduct into the uterus. This decrease in glucose and lactate appearances may be due to the decrease in oestrogen or the increase in progesterone concentrations, or both, after ovulation. 


\section{Effect of modulators of oviductal fluid secretion}

The effect of agonists that influence fluid secretion can be assessed electrophysiologically. In the intestine, histamine, platelet-activating factor (PAF), prostaglandin and ATP increase the potential difference, $\mathrm{I}_{\mathrm{scc}}$ and $\mathrm{Cl}^{-}$flux, thereby activating the secretory process (Hardcastle and Hardcastle, 1987; Hanglow et al., 1989). Brunton and Brinster (1971) applied the Ussing preparation to rabbit oviduct sheets and found that the potential difference and $I_{\text {scc }}$ were increased sharply by adrenaline, noradrenaline, isoproterenol and phenylephrine applied to the basal compartment. These responses were completely blocked by propranolol, indicating the presence of $\beta$-adrenergic receptors. Since such agents act in other systems by increasing cyclic AMP concentrations, Leese and Gray (1985) and Gott et al. (1988) tested the effect on oviductal fluid secretion of addition of CAMP to the medium perfusing the aviculture of isolated rabbit oviducts. CAMP and agents that mimicked its effect (cholera toxin, forskolin and theophylline) abolished oviductal fluid appearance and inhibited chloride secretion. This was an unexpected finding since, in other $\mathrm{Cl}^{-}$ secretory epithelia, cAMP stimulates $\mathrm{Cl}^{-}$and water transport. However, confirmation of this finding was provided by Dickens and Leese (1994) and Tay et al. (1997) using vascular perfusion of rabbit and human oviducts, respectively, and by Dickens et al. (1993, 1996) using the preparation for maintaining rabbit and human polarized oviduct epithelial cells grown in primary culture already described. In the human oviduct, Tay et al. (1997) showed that isoproterenol increased oviductal fluid formation sharply and could induce fluid appearance in the lumen of oviducts in which no fluid was being produced. Similarly, adrenaline, administered to the medium bathing the basal surface of rabbit epithelial cells increased basal to apical $\mathrm{Cl}^{-}$flux, as would be expected for an agonist that stimulated secretion. Conversely, addition of CAMP, the putative mediator of adrenaline action, to the basal medium increased apical to basal $\mathrm{Cl}^{-}$flux, that is, increased flow in the absorptive rather than the secretory direction. A similar paradox is observed in human tracheal epithelium in which agents expected to increase cAMP have little or no effect on $\mathrm{Cl}^{-}$ secretion. In this tissue, it was concluded that agents that increase CAMP failed to alter $\mathrm{Cl}^{-}$flux because the apical tissue-membrane conductance regulator (CFTR) was already fully open at resting CAMP concentrations. If $\mathrm{Cl}^{-}$channels are substantially open at basal cAMP concentrations, activation of $\mathrm{Ca}^{2+}$-dependent basolateral $\mathrm{K}^{+}$ channels, resulting in hyperpolarization of the apical membrane, can provide the driving force for net efflux of $\mathrm{Cl}^{-}$through the open CFTR (Yamaya et al., 1993). In other words, it is possible that, in the oviduct, as in human tracheal epithelium, $\mathrm{Cl}^{-}$flux increase is effected via $\mathrm{Ca}^{2+}$ dependent mechanisms rather than by cAMP, providing an explanation for the paradoxical effect of CAMP in diminishing oviductal fluid production.

\section{Purinergic agents}

Biological responses to extracellular ATP have been documented in virtually every major organ or tissue studied (for review, see Dubyak and El-Moatassim, 1993). Although ATP is present in millimolar concentrations in the cytosol of all cell types, extremely low extracellular concentrations of the nucleotide are normally maintained by the activity of ATPases and phosphatases and by the low permeability of ATP across lipid bilayer membranes. Therefore, appreciable concentrations of extracellular ATP will occur only transiently and in response to specific physiological conditions or stimuli or to pathological conditions. Such mechanisms include exocytotic release of ATP specifically concentrated within secretory granules, release of cytosolic ATP via intrinsic plasma membrane channels or pores, or sudden breakage of intact cells as in trauma or cell death. Effects of ATP are mediated through specific receptors termed $\mathrm{P}_{2}$-purinergic receptors $\left(\mathrm{P}_{1}\right.$-purinergic receptors are those mediating the effects of adenosine). There are at least four major classes of $\mathrm{P}_{2}$-purinergic receptors for ATP: $\mathrm{P}_{2 \mathrm{x}^{-}}$, $P_{2 y^{-}}, P_{2 u^{-}}$(or $5^{\prime}$-nucleotide) and $P_{2 z^{-}}$-receptors. $P_{2 y^{-r e c e p t o r s ~}}$ function as $G$ protein-coupled $\mathrm{Ca}^{2+}$ mobilizing ATP receptors, $\mathrm{P}_{2 \mathrm{x}}$-type receptors act as ligand-gated ion channels and $\mathrm{P}_{2 \mathrm{z}}$-receptors are associated with ATPinduced pore formation. In addition, there is another $G$ protein-coupled $\mathrm{Ca}^{2+}$-mobilizing nucleotide receptor, the $\mathrm{P}_{2 \mathrm{u}}$-receptor. This receptor is functionally similar to, but pharmacologically distinct from, the $P_{2 y}$-receptor in that UTP is a more potent agonist for it than is ATP. It is the $P_{2 u^{-}}$ receptor that appears to predominate in oviductal epithelial cells; in fact, this receptor may be one of the more widely expressed of the various ATP receptors. Activation of the $\mathrm{P}_{2 \mathrm{u}}$-receptor will be associated with an increase in intracellular calcium $\left(\left[\mathrm{Ca}^{2+}\right]_{\mathrm{i}}\right)$. Cox and Leese (1995) showed that ATP induced a transient increase in transepithelial potential difference and $\left[\mathrm{Ca}^{2+}\right]_{i}$ in bovine oviductal epithelial cells, a finding confirmed by Squires et al. (1995). Comparison of the effects of ATP, UTP and ADP showed that the receptors involved were, indeed, of the $\mathrm{P}_{2 \mathrm{u}}$ class. Similar effects of ATP have been reported for the oviduct from rabbit and human (Dickens et al., 1996; Downing et al., 1997; Fig. 2). Downing et al. (1997) and Reischl et al. (1999) showed that these ATP effects were, in part, mediated by $\mathrm{Cl}^{-}$ions, since the increase in transepithelial potential difference in response to ATP was reduced or abolished by pretreatment of the cells with chloride-channel blocking agents. Enhanced chloride secretion has been shown to be dependent on an increase in $\left[\mathrm{Ca}^{2+}\right]_{i}$ effected either by the release from intracellular stores or influx of extracellular $\mathrm{Ca}^{2+}$. Increased transepithelial flux of chloride ions would result in increased oviductal fluid secretion. The functional significance of ATP actions is unknown but they might provide a means by which spermatozoa and early embryos signal to the maternal tract. This hypothesis requires that spermatozoa and early embryos release ATP. Interactions 
between oviduct epithelia and spermatozoa (Baillie et al., 1997; Suarez, 1998) include the observation that the frequency of ciliary beat of oviduct ciliated cells increases markedly after spermatozoa are added to oviductal cell monolayers (Morales et al., 1996). Interactions between the early embryo and the oviduct have also been noted; fertilized embryos are transported down the oviduct at a faster rate than unfertilized ova in hamsters (Ortiz et al, 1986) and mares (Weber et al., 1991). Prostaglandins and PAF released by the embryo have been suggested as the signalling factors. Embryo-secreted factors also stimulate the frequency of ciliary beat in oviduct ciliated cells (Hermoso and Villalon, 1995). ATP also increases the beat frequency of human oviductal ciliated cells (Villalon et al., 1989), an effect associated with transient increases in $\left[\mathrm{Ca}^{2+}\right]_{\mathrm{i}}$, indicating that ATP is a candidate for a spermembryo secreted signalling factor acting on the oviduct epithelium.

\section{Nervous control of oviductal fluid}

The role of the autonomic nervous system in oviductal function is understood only partially. Sympathetic neurotransmitters undoubtedly modulate smooth muscle contractions of the oviduct, which, in turn, may influence oviductal transport of gametes and embryos. The innervation of the oviduct may also influence oviductal fluid production and secretion indirectly via an effect on blood flow since blood flow to the oviduct is implicated in the production and maintenance of oviductal fluid. Factors controlling the tone of the blood vessels supplying the oviduct would be expected to affect its luminal environment. A dense sympathetic adrenergic innervation exerts tonic vasoconstrictor control on the vasculature of the oviduct (for review, see Garcia-Pascual et al., 1996). Cholinergic innervation of the oviduct is scarce, although acetylcholine has a vasodilatory effect, possibly acting on endothelial receptors, stimulating release of nitric oxide, which relaxes oviductal arteries. A high density of neuropeptide $\mathrm{Y}$ - and vasointestinal peptidecontaining nerve fibres has been observed in relation to oviductal blood vessels, but their roles remain to be established. Further work is necessary to determine the extent of nervous control of oviductal secretion and to bring the level of understanding of the integrated control of oviduct function up to that available for epithelia of other tissues (Cooke, 1994).

\section{Clinical implications}

\section{Inflammatory mediators}

Infection of the female upper genital tract leading to inflammation is an increasing major health problem worldwide. Pelvic inflammatory disorder (PID) is a genital tract infection that affects at least 1 in 100 sexually active women. Undetected and untreated, PID can lead to chronic pelvic pain, oviductal damage, infertility and ectopic pregnancy. However, little is known about the biological

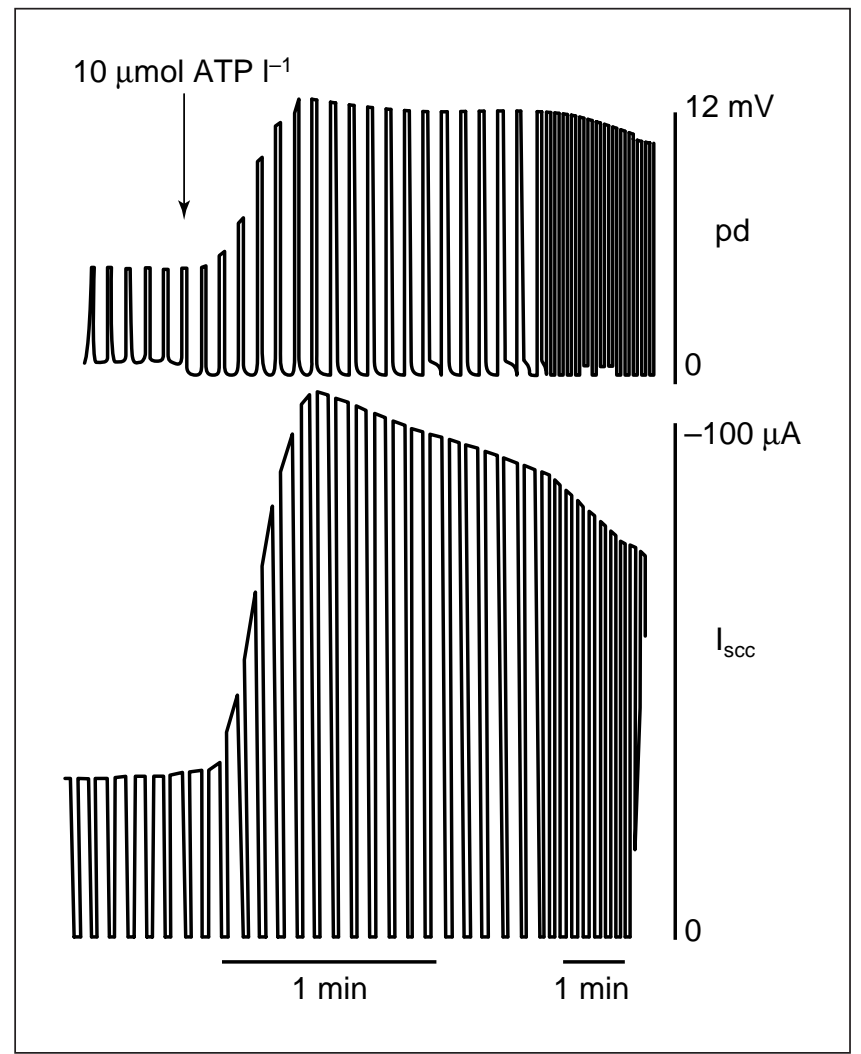

Fig. 2. Transepithelial potential difference $(p d)$ and $I_{\text {scc }}$ of human Fallopian tube epithelial cells grown in primary culture to confluency on a permeable support (see Fig. 1). Transepithelial potential difference and short circuit current $\left(\mathrm{I}_{\mathrm{scc}}\right)$ are measured using pairs of glass $\mathrm{KCl}$-filled electrodes and the cells are alternately clamped electrically at $0 \mathrm{mV}$ for $5 \mathrm{~s}$ and $+5 \mu \mathrm{A}$ for $1 \mathrm{~s}$, which permits almost simultaneous recording of potential difference and current, and allows resistance to be calculated using Ohm's law. The effect of ATP $\left(10 \mu \mathrm{mol} \mathrm{I}^{-1}\right)$ added to the medium bathing the apical surface of the cells can be seen as a marked increase in both potential difference and $\mathrm{I}_{\mathrm{scc}}$.

basis of the oviductal inflammation and the mechanisms by which the inflammatory response is sustained (Leese et al., 1996). Infection by Chlamydia trachomatis or Neisseria gonorrhoeae appear to be the commonest causes of PID, although with somewhat different results. Oviductal infection by $\mathrm{N}$. gonorrhoeae results in loss of ciliated cells, whereas repeated Chlamydial infections result in intraoviductal adhesions and distal oviductal obstruction. The risk of oviductal damage after the first episode of PID is $12.8 \%$, increasing to $35.5 \%$ after the second and $75 \%$ after the third episode (Westrom, 1975).

Downing et al. (1999) reported pronounced effects of the inflammatory agent histamine on human oviductal epithelial cell electrophysiology, on $\left.\mathrm{CCa}^{2+}\right]_{i}$ and on contractions of the myosalpinx. The effects of histamine are largely mediated by $\mathrm{H}_{1}$ receptors. Histamine was more active when applied basally than when applied apically, indicating that 


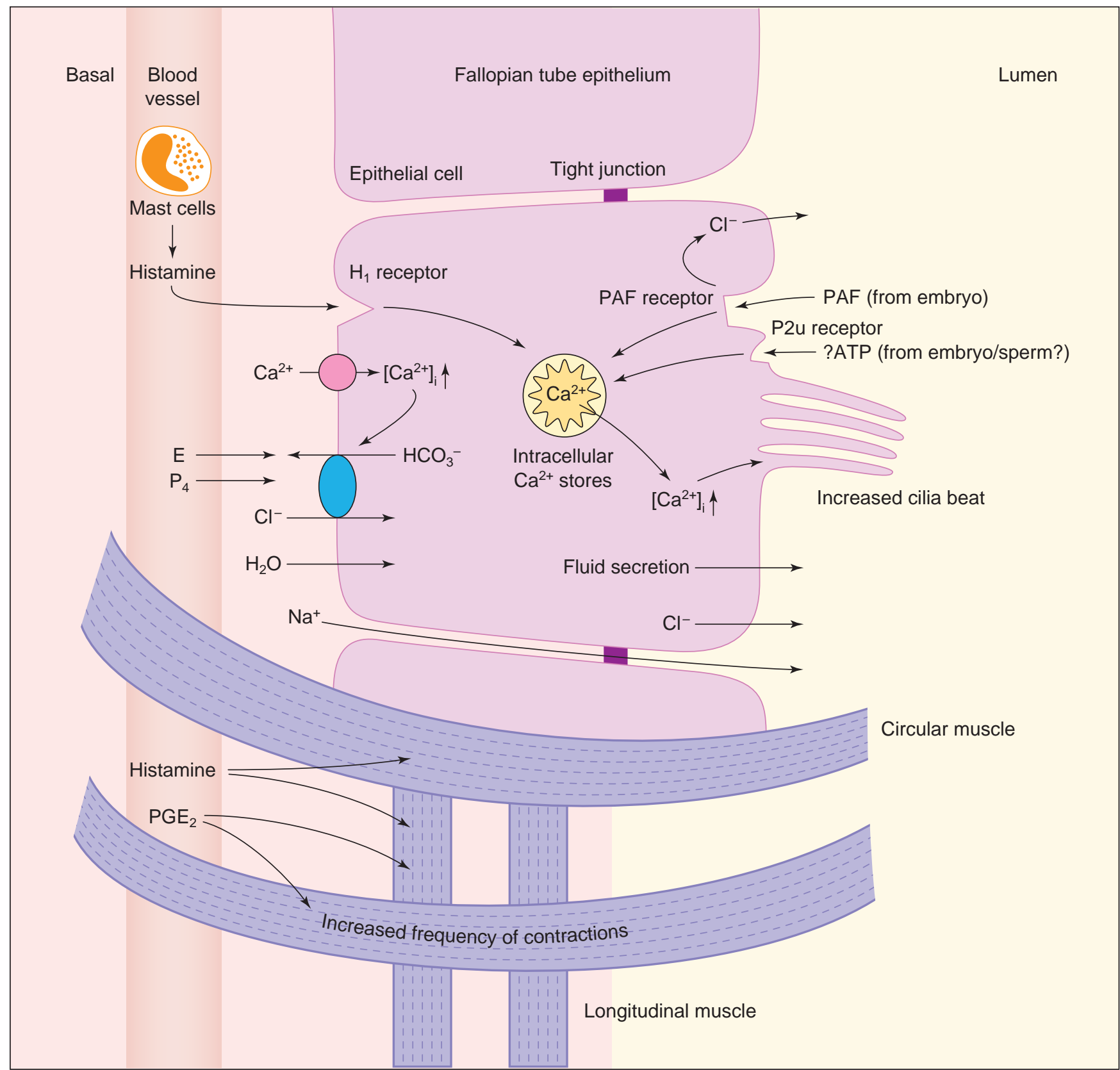

Fig. 3. Schematic diagram of a Fallopian tubal epithelial cell showing some of the influences on secretion of oviductal fluid and contraction of the oviductal smooth muscle. Oestrogen $(E)$ and progesterone $\left(\mathrm{P}_{4}\right)$, transported to the oviductal epithelium by the blood supply, may influence transepithelial flow of chloride ions and thus fluid secretion. Similarly, histamine secreted by mast cells in the blood influences intracellular calcium, which in turn influences chloride movements. Platelet-activating factor (PAF) and ATP, from the embryo or spermatozoa, or both, influence intracellular calcium concentrations, chloride fluxes and ciliary beat frequency. $\mathrm{PGE}_{2}$, prostaglandin $\mathrm{E}_{2}$. (Reproduced, with adaptations, with kind permission of Biology of Reproduction.)

its physiological origin in the oviduct is from mast cells. In contrast, PAF produced a marked increase in transepithelial potential difference when applied to the apical surface, indicating that, physiologically, it originates from the embryo, as proposed by Velasquez et al. (1995) and Stoddart et al. (1996). Histamine, together with prostaglandin $E_{2}$, also increases the contraction of oviductal circular and longitudinal muscle. These effects, summarized in Fig. 3, indicate that anti-inflammatory agents could benefit women with PID. Ironically, physicians may prescribe anti-inflammatory agents to patients with acute pelvic pain, by which treatment they may unwittingly have selected the appropriate drugs for reducing oviductal inflammation and excessive smooth muscle activity. The 
true potential for anti-inflammatory agents to alleviate PID needs to be tested in a properly conducted clinical trial.

\section{Hydrosalpinx}

Pelvic inflammatory disorder causes damage to the oviductal epithelial surface, fibrosis of the fimbriae and may lead to complete oviductal closure or extensive perioviductal adhesions. These effects result in the accumulation of oviductal fluids, which normally would drain into the pelvic cavity via the fimbrial ostium, and leads eventually to hydrosalpinx formation and infertility, since ova cannot enter the oviduct. In vitro fertilization or embryo transfer treatment of women with hydrosalpinx has been associated with reduced pregnancy rates after IVF and an increased incidence of miscarriage in the first trimester (Katz et al., 1996). Granot et al. (1998) suggested that the constant passage of fluid into the uterine cavity produces mechanical interference that is responsible for the failure of implantation. Release of cytokines, prostaglandins and inflammatory components may also reduce endometrial receptivity. Hydrosalpinx fluid may be embryotoxic or may lack components essential for early embryo development (for review, see Lass, 1999), accounting for the poor outcome after IVF. Agents such as propranolol, which reduce oviductal fluid production, could be valuable in the prevention of hydrosalpinx formation. As with the use of anti-inflammatory agents in treating pelvic pain, this possibility needs to be subject to clinical trial.

\section{Conclusion}

The Fallopian tube is lined by a transporting epithelium, no different, in essence, from those that line the other internal and external surfaces of the body. It is hoped that this review will stimulate further research into oviductal epithelial transport mechanisms, ultimately, to help understanding and recreate the first environment of the embryo and develop improved therapies for oviductal disorders.

The authors' studies included in this review were funded by the Medical Research Council, the Wellcome Trust and the European Commission.

\section{References}

Key references are identified by asterisks.

Abe H and Hoshi H (1997) Bovine oviductal epithelial cells: their cell culture and applications in studies for reproductive biology Cytotechnology 23 171-183

Abe H, Satoh T and Hoshi H (1998) Primary modulation by oestradiol of the production of an oviduct-specific glycoprotein by the epithelial cells in the oviduct of the new-born golden hamster Journal of Reproduction and Fertility 112 157-163

Baillie HS, Pacey AA, Warren MA, Scudamore IW and Barratt CLR (1997) Greater numbers of human spermatozoa associate with endosalpingeal cells derived from the isthmus compared with those from the ampulla Human Reproduction 12 1985-1992

Bishop DW (1956) Active secretion in the rabbit oviduct American Journal of Physiology 187 347-352
* Boatman DE (1997) Response of gametes to the oviductal environment Human Reproduction 12 (Supplement) 133-149

Boatman DE and Magnoni GE (1995) Identification of a sperm penetration factor in the oviduct of the golden hamster Biology of Reproduction $\mathbf{5 2}$ 199-207

Brunton WJ and Brinster RL (1971) Active chloride transport in the isolated rabbit oviduct American Journal of Physiology 221 658-661

Comer MT, Leese HJ and Southgate J (1998) Induction of a differentiated ciliated cell phenotype in primary cultures of Fallopian tube epithelium Human Reproduction 13 3114-3120

Cooke HJ (1994) Neuroimmune signalling in regulation of intestinal ion transport American Journal of Physiology 266 G167-G178

*Cox Cl and Leese HJ (1995) Effect of purinergic stimulation on intracellular calcium concentration and transepithelial potential difference in cultured bovine oviduct cells Biology of Reproduction 52 1244-1249

Dawson KM, Collins JL and Baltz JM (1998) Osmolarity-dependent glycine accumulation indicates a role for glycine as an organic osmolyte in early preimplantation mouse embryos Biology of Reproduction 59 225-232

Demott RP, Lefebvre R and Suarez SS (1995) Carbohydrates modulate the adherence of hamster sperm to oviductal epithelium Biology of Reproduction 52 1395-1403

Diamond JM (1971) Standing-gradient model of fluid transport in epithelia Federation Proceedings 30 6-13

Dickens CJ and Leese HJ (1994) The regulation of rabbit oviduct fluid formation Journal of Reproduction and Fertility 100 577-581

Dickens CJ, Southgate J and Leese HJ (1993) Use of primary cultures of rabbit oviduct epithelial cells to study the ionic basis of tubal fluid formation Journal of Reproduction and Fertility 98 603-610

Dickens CJ, Maguiness SD, Comer MT, Palmer A, Rutherford AJ and Leese HJ (1995) Human tubal fluid formation and composition during vascular perfusion of the Fallopian tube Human Reproduction 10 505-508

*Dickens CJ, Comer MT, Southgate J and Leese HJ (1996) Human Fallopian tubal epithelial cells in vitro: establishment of polarity and potential role of intracellular calcium and extracellular ATP in fluid secretion Human Reproduction $11212-217$

Downing SJ, Maguiness SD, Watson A and Leese HJ (1997) Electrophysiological basis of human Fallopian tubal fluid formation Journal of Reproduction and Fertility 111 29-34

Downing SJ, Chambers EL, Maguiness SD, Watson A and Leese HJ (1999) Effect of inflammatory mediators on the electrophysiology of the human oviduct Biology of Reproduction 61 657-664

Dubyak GR and El-Moatassim C (1993) Signal transduction via $P_{2-}$ purinergic receptors for extracellular ATP and other nucleotides American Journal of Physiology 265 C577-C606

Edwards LJ and Leese HJ (1993) Glucose transport and metabolism in rabbit oviduct epithelial cells Journal of Reproduction and Fertility 99 585-591

Garcia-Pascual A, Labadia A, Triguero D and Costa G (1996) Local regulation of oviductal blood flow General Pharmacology 27 $1303-1310$

Gardner DK, Lane M, Calderon I and Leeton J (1996) Environment of the human preimplantation embryo in vivo: metabolite analysis of oviduct and uterine fluids and metabolism of cumulus cells Fertility and Sterility 65 349-353

Gott AL, Gray SM, James AF and Leese HJ (1988) The mechanism and control of rabbit oviduct fluid formation Biology of Reproduction 39 758-763

Granot I, Dekel N, Fieldust S, Shoham Z and Baresh A (1998) Is hydrosalpinx fluid cytotoxic? Human Reproduction 6 1620-1624

Hanglow AC, Bienenstock J and Perdue M (1989) Effects of plateletactivating factor on ion transport in isolated rat jejunum American Journal of Physiology 257 G845-G850

Hardcastle J and Hardcastle PT (1987) The secretory actions of histamine in rat small intestine Journal of Physiology 388 521-532

Hermoso MA and Villalon MJ (1995) Embryo secreted factors increase the frequency of ciliary beat of hamster oviduct cells in vitro. Biology of Reproduction $\mathbf{5 2}$ Supplement $\mathbf{1} 180$

Hunter RHF (1988) Fallopian tube fluid: the physiological medium for fertilization and early embryo development. In The Fallopian Tubes: Their Role in Fertility and Infertility pp 30-52. Springer-Verlag, Berlin 
Hunter RHF (1994) Modulation of gamete and embryonic microenvironments by oviduct glycoproteins Molecular Reproduction and Development 39 176-181

Katz E, Akman MA, Damewood MD and García JE (1996) Deleterious effect of the presence of hydrosalpinx on implantation and pregnancy rates with in vitro fertilization Fertility and Sterility 66 122-125

Lass A (1999) What effect does hydrosalpinx have on assisted reproduction? What is the preferred treatment for hydrosalpinges? The ovary's perspective Human Reproduction 14 1674-1677

Leese HJ (1983) Studies on the movement of glucose, pyruvate and lactate into the ampulla and isthmus of the rabbit oviduct Quarterly Journal of Experimental Physiology 68 89-96

Leese HJ (1988) The formation and function of oviduct fluid Journal of Reproduction and Fertility 82 843-856

Leese HJ and Gray SM (1985) Vascular perfusion: a novel means of studying oviduct function American Journal of Physiology 248 E624-E632

*Leese HJ, Maguiness SD, Killick SR and Trejdosiewicz LK (1996) Infection in the human Fallopian tube: secretory and immune responses. In The Prevention of Pelvic Infection pp 92-101 Ed. A Templeton. RCOG Press, London

McDonald MF and Bellvé AR (1969) Influence of oestrogen and progesterone on flow of fluid from the Fallopian tube in the ovariectomized ewe Journal of Reproduction and Fertility 20 51-61

Martus NS, Verhage HG, Mavrogiannis PA and Thibodeaux JK (1998) Enhancement of bovine oocyte fertilization in vitro with a bovine oviductal specific glycoprotein Journal of Reproduction and Fertility 113 323-329

Mastroianni L, Beer F, Shah V and Clewe TH (1961) Endocrine regulation of oviduct secretions in the rabbit Endocrinology 68 92-100

Miller JGO and Schultz GA (1987) Amino acid content of preimplantation rabbit embryos and fluids of the reproductive tract Biology of Reproduction 36 125-129

Morales P, Palma V, Salgado M and Villalon M (1996) Sperm interaction with human oviductal cells in vitro. Human Reproduction 11 1504-1509

Murray MK (1995) Epithelial lining of the sheep ampulla oviduct undergoes pregnancy-associated morphological changes in secretory status and cell height Biology of Reproduction 53 653-663

Nichol R, Hunter RHF, Gardner DK, Leese HJ and Cooke GM (1992) Concentrations of energy substrates in oviductal fluid and blood plasma during the peri-ovulatory period Journal of Reproduction and Fertility 96 699-707

Nichol R, Hunter RHF, Gardner DK, Partridge R, Leese HJ and Cooke GM (1998) Concentrations of energy substrates in oviduct fluid in unilaterally ovariectomized pigs Research in Veterinary Science $\mathbf{6 5}$ 263-264

Oliphant G, Cabot C, Ross P and Marta J (1984) Control of the humoral immune system within the rabbit oviduct Biology of Reproduction 31 205-212

Ortiz ME, Bedregal P, Carvajal MI and Croxatto HB (1986) Fertilized and unfertilized ova are transported at different rates by the hamster oviduct Biology of Reproduction 34 777-781

Perkins JL (1974) Fluid flow of the oviduct. In The Oviduct and its Functions pp 119-132 Eds AD Johnson and CW Foley. Academic Press, New York, London

Quinton PM (1990) Cystic fibrosis: a disease in electrolyte transport FASEB Journal 4 2709-2717

Reischl J, Downing SJ and Leese HJ (1999) Electrophysiological studies on bovine oviduct epithelial cells in primary culture Journal of Reproduction and Fertility Abstract Series 23 Abstract 52
Reischl J, Downing SJ and Leese HJ (2000) lon transport in bovine oviduct epithelial cells Theriogenology 5347

Richardson LL and Oliphant G (1981) Steroid concentrations in rabbit oviducal fluid during oestrus and pseudopregnancy Journal of Reproduction and Fertility 62 427-431

Roberts GP, Parker JM and Symonds HW (1975) Proteins in the luminal fluid from the bovine oviduct Journal of Reproduction and Fertility $\mathbf{4 5}$ 301-313

Squires PE, Hill CJ, Pacey AA, Li TC, Cooke ID, Warren MA and Dunne MJ (1995) Purinergic receptor-mediated increases in intracellular $\mathrm{Ca}^{2+}$ in single isolated epithelial cells of the human uterine tube Journal of Physiology London 482P P45

Staros AL and Killian GJ (1998) In vitro association of six oviductal fluid proteins with the bovine zona pellucida Journal of Reproduction and Fertility 112 131-137

Stoddart NR, Wild AE and Fleming TP (1996) Stimulation of development in vitro by platelet activating factor receptor ligands released by mouse preimplantation embryos Journal of Reproduction and Fertility 108 47-53

Suarez SS (1998) The oviductal sperm reservoir in mammals: mechanisms of formation Biology of Reproduction 58 1105-1107

Sun T, Lei ZM and Rao CV (1998) A novel regulation of the oviductal glycoprotein gene expression by luteinizing hormone in bovine tubal epithelial cells Molecular and Cellular Endocrinology 131 97-108

*Tay JI, Rutherford AJ, Killick SR, Maguiness SD, Partridge RJ and Leese HJ (1997) Human tubal fluid: production, nutrient composition and response to adrenergic agents Human Reproduction 12 2451-2456

Ussing $\mathbf{H}$ and Zerahn K (1951) Active transport of sodium as the source of electric current in the short-circuited isolated frog skin Acta Physiologica Scandinavica 23 110-127

Van Winkle LJ, Haghighat N and Campion AL (1990) Glycine protects preimplantation mouse conceptuses from a detrimental effect of the inorganic ions in oviductal fluid Journal of Experimental Zoology 253 215-219

Velasquez LA, Aguilera JG and Croxatto HB (1995) Possible role of plateletactivating factor in embryonic signalling during transport in the hamster Biology of Reproduction 52 1302-1306

*Verhage HG, Fazleabas AT, Mavrogiannis PA, O'Day-Bowman MB Donelly KM, Arias EB and Jaffe RC (1997) The baboon oviduct: characteristics of an oestradiol-dependent oviduct-specific glycoprotein Human Reproduction Update 3 541-552

Verlander JW, Tran TM, Zhang L, Kaplan MR and Hebert SC (1998) Estradiol enhances thiazide-sensitive $\mathrm{NaCl}$ cotransporter density in the apical plasma membrane of the distal convoluted tubule in ovariectomized rats Journal of Clinical Investigation 101 1661-1669

Villalon M, Hinds TR and Verdugo P (1989) Stimulus-response coupling in mammalian ciliated cells. Demonstration of two mechanisms for control of cytosolic calcium Biophysical Journal 56 1255-1258

Weber JA, Freeman DA, Vanderwall DK and Woods GL (1991) Prostaglandin E2 hastens oviductal transport of equine embryos Biology of Reproduction 45 544-546

Westrom L (1975) Effect of acute pelvic inflammatory disease on fertility American Journal Obstetrics and Gynecology 121 707-713

Yamaya M, Ohrui T, Finkbeiner WE and Widdicombe JH (1993) Calciumdependent chloride secretion across cultures of human tracheal surface epithelium and glands American Journal of Physiology 265 L170-L177

Zeitlin PL, Wagner M, Markakis D, Loughlin GM and Guggino WB (1989) Steroid hormones: modulators of $\mathrm{Na}^{+}$absorption and $\mathrm{Cl}^{-}$secretion in cultured tracheal epithelia Proceedings National Academy of Sciences USA 86 2502-2505 